Article

\title{
The Forgotten Agenda of Wasting in Southeast Asia: Burden, Determinants and Overlap with Stunting: A Review of Nationally Representative Cross-Sectional Demographic and Health Surveys in Six Countries
}

\author{
Mueni Mutunga ${ }^{1, *}$, Severine Frison ${ }^{2}$, Matteo Rava ${ }^{3}$ and Paluku Bahwere ${ }^{4}$ \\ 1 United Nations Children's Fund (UNICEF) East Asia Pacific Regional Office, Bangkok 10200, Thailand \\ 2 Department of Infectious Disease Epidemiology, London School of Hygiene and Tropical \\ Medicine (LSHTM), London WC1E 7HT, UK; severine.frison@lshtm.ac.uk \\ 3 Bergen Center for Ethics and Priority Setting (BCEPS), University of Bergen, 5009 Bergen, Norway; \\ matteorava.moh@gmail.com \\ 4 Centre de Recherche en Epidémiologie, Biostatistique et Recherche Clinique, Ecole de Santé Publique, \\ Université Libre de Bruxelles, 1080 Brussels, Belgium; paluku.bahwere@ulb.ac.be \\ * Correspondence: mmutunga@unicef.org
}

Received: 9 January 2020; Accepted: 3 February 2020; Published: 20 February 2020

\begin{abstract}
Childhood wasting is among the most prevalent forms of undernutrition globally. The Southeast Asia region is home to many wasted children, but wasting is not recognized as a public health problem and its epidemiology is yet to be fully examined. This analysis aimed to determine the burden of wasting, its predictors, and the level of wasting and stunting concurrence. Datasets from Demographic and Health Surveys and Multiple Indicator Cluster Surveys in six countries in the region were analyzed. The pooled weighted prevalence for wasting and concurrent wasting and stunting among children 0-59 months in the six countries was 8.9\%, 95\% CI (8.0-9.9) and $1.6 \%, 95 \%$ CI (1.5-1.8), respectively. This prevalence is approximately 12 -fold higher than the $0.7 \%$ prevalence of high-income countries; and translated into an absolute number of 1,088,747 children affected by wasting and 272,563 concurrent wasting and stunting. Wasting prevalence was 50 percent higher in the 0-23-month age group. Predictors for wasting included source of drinking water, wealth index, urban residence, child's age and history of illness and mother's body mass index. In conclusion, our analysis showed that wasting is a serious public health problem in the region that should be addressed urgently using both preventive and curative approaches.
\end{abstract}

Keywords: wasting; severe wasting; wasting and stunting; prevalence; burden; Southeast Asia; DHS; MICS; risk factors; under five

\section{Introduction}

Undernutrition in the first 1000 days post-conception has both short- and long-term detrimental consequences for the health and nutrition status of children, and adversely affects the economic productivity of nations [1]. It is associated with cognitive deficits that lead to lower educational performance [1-5], physical growth deficits that can limit economic productivity in adulthood [1,6,7], immune system dysfunction and reduced efficacy of vaccines-hence increased susceptibility to and severity of infections $[1,8,9]$. Among women, the consequences of undernutrition during childhood can persist until reproductive age and cause intrauterine growth restriction $[1,10]$. Wasting, a form of acute malnutrition, is diagnosed in children 6 to 59 months old when the weight-for-height z-score (WHZ) of WHO child growth standards is $<-2$ standard deviations (SD). It is one of the most prevalent 
forms of undernutrition, is associated with high short-term mortality and some studies have shown that it also contributes significantly to linear growth restriction [11-13]. Studies have shown that a child with severe wasting, also called severe acute malnutrition (SAM), is up to 12 times more likely to die than a well-nourished child [14-16], and the survivors of SAM episodes have an increased risk of developing non-communicable chronic diseases during adulthood [1,17-20]. Recent studies have shown that children who are both wasted and stunted are at a higher risk of death than those with only one of the two nutritional deficits [21].

The standardization of the SAM management, by the World Health Organization (WHO) and the adoption of the community-based management of acute malnutrition (CMAM) have contributed to the tremendous reduction in SAM case fatality [22-26]. However, the coverage of interventions addressing SAM remains low in the Southeast Asia region as observed by Ahmed et al. in their review paper published in 2014 that covered, Cambodia, Myanmar, Timor-Leste, Lao PDR and Vietnam among other countries in the Asia region [27]. This is despite the region being widely known to be home to a large number of wasted children [28]. Studies have demonstrated that wasted Asian children, regardless of the region, respond well to treatment based on the WHO protocol and that premature interruption of this treatment is associated with increased risk of death during the weeks following the interruption [27,29-33]. The low coverage of SAM curative interventions is partly due to the belief that SAM observed in Asian children has different determinants and clinical features than those observed in African children [34-38]. This position shared by many policymakers in the Southeast Asia region limits provision of services to address wasting [5,27].

This article is based on a review of nationally representative surveys of selected countries in the Southeast Asia region to determine wasting burden, determinants and the overlap with stunting. It aims to contribute to the existing and growing body of evidence needed to support the prioritization of treatment of wasting in addition to the ongoing effort to prevent both wasting and stunting.

\section{Materials and Methods}

\subsection{Study Design}

The present study is a secondary data analysis of the latest Demographic and Health Survey (DHS) and Multiple Indicator Cluster Surveys (MICS) or National Food and Nutrition Survey (NFNS) (when DHS or MICS data is unavailable) from Cambodia, Lao PDR, Myanmar, Thailand, Timor-Leste and Vietnam.

\subsection{Datasets}

Data were from nationally representative cross-sectional surveys conducted between 2013 and 2017 in six Southeast Asian countries that had publicly available data. All the countries in the region were eligible, but nationally representative survey data were not publicly available all countries. These datasets used included the Cambodia Demographic and Health Survey (DHS) 2014, Lao PDR Multiple Indicator Cluster Surveys (MICS) 2017, Myanmar DHS 2015, Thailand MICS 2015/6, Timor-Leste National Food and Nutrition Survey (NFNS) 2013 and Vietnam MICS 2011.

All the surveys used multistage cluster sampling. Detailed sampling plans are available from the final survey reports. All the datasets included sampling weights used for the calculation of nationally representative statistics. For this regional analysis, data from each country were imported into Stata14.1 (Stata Corp) and merged for analysis.

\subsection{Analytic Sample}

Children under five years of age were included in the analysis if they had a plausible value for WHZ (i.e., ranging from -5 to 5 ). 


\subsection{Data Management and Analysis}

The primary outcomes for our analyses were wasting, stunting, and concurrence of wasting and stunting. Wasting was diagnosed when WHZ of WHO child growth standards was $<-2 \mathrm{SD}$, and severe wasting when WHZ was $<-3$ SD and $<-2$. Stunting was diagnosed when length/height-for-age z-score (HAZ) was $<-2$ SD and severe stunting when HAZ was $<-3 \mathrm{SD}$. Wasting and stunting concurrence was diagnosed when both WHZ and HAZ are <-2 SD. Entries with missing values of the child age, sex and any anthropometric measurement were excluded in the analysis. A two-stage approach to anthropometric data cleaning was applied. First we applied the biological plausibility criteria where values were set to missing if weight $>50 \mathrm{~kg}$ or if height $>200 \mathrm{~cm}$. Second, we applied the WHO statistical probability criteria where HAZ was set to missing if HAZ $>6$ or $<-6$ and WHZ was set to missing if $\mathrm{WHZ}>5$ or $<-5$. Additionally, any record with missing parameters for the calculation of WHZ or HAZ was dropped from the analysis.

\subsection{New Variable Creation}

Most variables were used as stored in the survey datasets and are presented in Table 1. Variables transformed to create a new variable were: child's age, for which six categories were created as per DHS and MICS categorization (Table 2); immunization status, for which a category "unsure" was added to minimize missing records for children for whom it was reported that they had a vaccination card, but the immunization timeliness could not be ascertained; and, number of antenatal care visits, for which a category "other" was added for respondents whose antenatal care visits were reported, but they could not fit into the category of being attended by a skilled staff or not.

\subsection{Data Analysis}

We calculated pooled and individual countries weighted prevalence of wasting, severe wasting and concurrence of wasting and stunting. We also calculated the burden (number of children affected) overall and for each country. To calculate the burden of wasting and concurrent wasting and stunting, we used the 0 to 59-month-old population for the corresponding country and survey year from the State of the World Children annual reports. The burden of wasting, severe wasting and concurrence of wasting and stunting were then estimated by multiplying the observed prevalence by the total population estimate for 0 to 59 -month-old children.

We used univariate and multivariate multilevel logistic regression to identify individual, household, maternal, and child characteristics significantly associated with wasting in the region. First, we developed three separate models for each level of characteristics, namely household model, mother model and child model. Subsequently, we constructed a combined model assessing all the covariates together. For all the models, we included all the variables available for analysis into the dataset and excluded only the covariates introducing collinearity. For all the combined models, we also excluded covariates associated with higher than $10 \%$ sample size reduction. No stepwise method was used, and significant and non-significant covariates are presented in the tables to show the effect of adjustment for all the covariates.

\subsection{Ethical Considerations}

Ethical approval for the analyses presented in this paper was not sought as the paper is based on data obtained after completed the mandatory registration to DHS Macro (http://dhsprogram.com/ data/Access-Instructions.cfm) and from United Nations Children's Fund (UNICEF) for Multi-indicator Cluster Surveys that serve as authorization to access the datasets for secondary analysis research. The authorization to use the Timor-Leste NFNS data was obtained from the National Office of Statistics, Timor-Leste. 
Table 1. Selected households, mothers and children characteristics by country.

\begin{tabular}{|c|c|c|c|c|c|c|c|}
\hline Characteristic & Cambodia & Lao PDR ${ }^{2}$ & Myanmar & $\begin{array}{l}\text { Country } \\
\text { Thailand }\end{array}$ & Timor-Leste & Vietnam & Total $^{1}$ \\
\hline Type of survey & DHS $^{3}$ & $\mathrm{MICS}^{4}$ & DHS & MICS & NFNS & MICS & \\
\hline Year of survey & 2014 & 2017 & 2015 & 2015/2016 & 2013 & 2011 & \\
\hline Households interviewed, $\mathrm{n}$ & 15825 & 22287 & 12500 & 28652 & & 11614 & \\
\hline Mothers/caretakers of children under 5 interviewed, $\mathrm{n}$ & 7165 & 11812 & 4815 & 12250 & 9443 & 3729 & 49214 \\
\hline Total analyzed sample, $\mathrm{n}$ & 7165 & 11812 & 4815 & 10551 & 9482 & 3729 & 47554 \\
\hline$\%$ rural residence in analyzed sample & 72.8 & 69.3 & 79.0 & 54.2 & 74.9 & 61.4 & 67.9 \\
\hline$\%$ improved water source & 67.1 & 80.7 & 79.3 & 97.9 & 63.8 & 67.9 & 80.0 \\
\hline Age of the mother distribution in analyzed sample & $n=7165$ & $n=11812$ & $n=4815$ & $n=10351$ & $n=9482$ & $n=3729$ & $n=47554$ \\
\hline$\%<20$ years & 2.4 & 6.7 & 2.2 & 4.7 & 3.1 & 2.3 & 4.1 \\
\hline$\% 20-35$ years & 53.5 & 72.1 & 67.7 & 62.2 & 65.3 & 74.4 & 65.5 \\
\hline$\% \geq 35$ years & 44.1 & 21.2 & 30.1 & 33.1 & 31.6 & 23.3 & 30.4 \\
\hline Mother's marital status & $n=7165$ & $n=11168$ & $n=4815$ & $n=10453$ & $n=9942$ & $n=3523$ & $n=46566$ \\
\hline$\%$ in union & 94.5 & 97.5 & 95.3 & 93.8 & 97.2 & 97.4 & 95.9 \\
\hline Highest level of education of the mothers in analyzed sample & $n=7165$ & 11720 & $n=4815$ & $n=10500$ & $n=9456$ & $n=3431$ & \\
\hline No formal education & 14.4 & 22.9 & 17.9 & 0.0 & 31.0 & 0.0 & \\
\hline$\%$ Primary & 49.4 & 38.9 & 44.3 & 3.7 & 26.1 & 19.7 & \\
\hline$\%$ Secondary & 32.4 & 20.5 & 31.0 & 22.0 & 17.3 & 60.3 & \\
\hline$\%$ Higher than secondary & 3.8 & 17.7 & 6.8 & 74.3 & 25.6 & 20.0 & \\
\hline Height of the mothers in analyzed sample & $n=4703$ & $n=0$ & $n=4757$ & $n=0$ & $n=9271$ & $n=0$ & \\
\hline$<145 \mathrm{~cm}$ & 5.9 & & 8.1 & & 13.3 & & \\
\hline$\geq 145 \mathrm{~cm}$ & 94.1 & & 91.9 & & 86.7 & & \\
\hline BMI of mothers $\left(\mathrm{kg} \cdot \mathrm{m}^{-2}\right)$ & $n=4699$ & $n=0$ & $n=4753$ & $n=0$ & $n=9253$ & $n=0$ & \\
\hline$\%<18.5$ & 11.5 & & 10.4 & & 25.7 & & \\
\hline$\%$ 18.5-25.0 & 71.3 & & 67.1 & & 64.8 & & \\
\hline$\% 25.0-30.0$ & 14.4 & & 17.8 & & 8.4 & & \\
\hline$\% \geq 30.0$ & 2.7 & & 4.7 & & 1.1 & & \\
\hline Antenatal care by skilled provider & $n=5560$ & $n=11812$ & $n=3311$ & $n=10551$ & $n=7840$ & $n=3729$ & $n=42803$ \\
\hline$\geq 4$ & 78.5 & 58.3 & 66.1 & 67.7 & 76.7 & 76.4 & 68.7 \\
\hline$<4$ & 21.5 & 41.7 & 33.9 & 32.3 & 23.3 & 23.6 & 31.3 \\
\hline Distribution of sex among surveyed under 5 children & $n=7165$ & $n=11812$ & $n=4815$ & $n=10551$ & $n=9409$ & $n=3729$ & $n=47481$ \\
\hline$\%$ male & 50.4 & 50.9 & 52.5 & 51.2 & 51.1 & 51.0 & 51.1 \\
\hline Size at birth & $n=7122$ & $n=6170$ & $n=4631$ & $n=4143$ & $n=0$ & $n=1665$ & \\
\hline Very large than average & 4.1 & 2.1 & 1.6 & 1.8 & & 1.3 & \\
\hline Large than average & 31.3 & 12.6 & 22.6 & 17.4 & & 10.2 & \\
\hline Average & 53.1 & 77.2 & 61.9 & 70.8 & & 78.7 & \\
\hline Small than average & 8.9 & 7.7 & 12.5 & 9.3 & & 8.3 & \\
\hline Very small than average & 2.6 & 0.4 & 1.5 & 0.6 & & 1.6 & \\
\hline
\end{tabular}


Table 1. Cont.

\begin{tabular}{|c|c|c|c|c|c|c|c|}
\hline Characteristic & Cambodia & Lao PDR ${ }^{2}$ & Myanmar & $\begin{array}{l}\text { Country } \\
\text { Thailand }\end{array}$ & Timor-Leste & Vietnam & Total $^{1}$ \\
\hline Age distribution (\%) of surveyed under 5 children (in months) & $n=7165$ & $n=11720$ & $n=4815$ & $n=10500$ & $n=9460$ & $n=3678$ & $n=47338$ \\
\hline $0-5$ & 10.0 & 9.7 & 10.3 & 5.9 & 12.0 & 8.7 & 9.3 \\
\hline $6-11$ & 10.9 & 10.4 & 10.0 & 6.3 & 13.4 & 9.5 & 10.0 \\
\hline $12-23$ & 20.6 & 18.9 & 19.6 & 20.7 & 25.3 & 20.7 & 21.0 \\
\hline 24-35 & 19.8 & 20.3 & 19.7 & 22.3 & 21.0 & 21.4 & 20.9 \\
\hline $36-47$ & 18.8 & 21.4 & 21.1 & 23.0 & 17.1 & 20.9 & 20.5 \\
\hline $48-59$ & 19.9 & 19.3 & 19.3 & 21.8 & 11.2 & 18.8 & 18.3 \\
\hline Breast feeding practices & $n=7153$ & $n=8015$ & $n=4815$ & $n=6265$ & $n=4758$ & $n=3604$ & $n=34610$ \\
\hline$\%$ ever breastfed & 95.4 & 100.0 & 97.4 & 100.0 & 89.0 & 100.0 & 97.2 \\
\hline
\end{tabular}

${ }^{1}$ total not calculated when data missing for any of the countries; ${ }^{2}$ PDR = People's Democratic Republic; ${ }^{3}$ DHS $=$ Demographic Health Survey; ${ }^{4}$ MICS $=$ Multiple Indicator Cluster Survey.

Table 2. Pooled and by country prevalence and burden of wasting and severe wasting.

\begin{tabular}{|c|c|c|c|c|c|c|c|}
\hline \multirow{2}{*}{ Country } & \multirow{2}{*}{ Year of survey } & \multirow{2}{*}{ Total under 5 population ${ }^{1}$} & \multirow{2}{*}{ Sample Size } & \multicolumn{2}{|c|}{ Prevalence $\left(95 \% \mathrm{CI}^{2}\right)$} & \multicolumn{2}{|c|}{ Burden ${ }^{3}$ (Number of Affected) } \\
\hline & & & & Wasted $^{4}$ & Severely Wasted ${ }^{5}$ & Wasted ${ }^{4}$ & Severely Wasted ${ }^{5}$ \\
\hline Cambodia & 2014 & $1,742,000$ & 4359 & $10.0(8.9 ; 11.2)$ & $2.6(2.1 ; 3.4)$ & 174200 & 45292 \\
\hline Lao PDR 6 & 2017 & 777,000 & 11362 & $9.0(8.3 ; 9.8)$ & $3.0(2.6 ; 3.4)$ & 69930 & 23310 \\
\hline Myanmar & 2015 & $4,565,000$ & 4200 & $6.8(5.9 ; 7.9)$ & $1.4(1.0 ; 1.9)$ & 310420 & 63910 \\
\hline Thailand & $2015 / 16$ & $3,784,000$ & 9541 & $5.8(4.6 ; 7.3)$ & $1.5(1.0 ; 2.4)$ & 219472 & 56760 \\
\hline Timor-Leste & 2013 & 190,000 & 9257 & $10.6(9.4 ; 11.9)$ & $2.3(1.8 ; 2.9)$ & 20140 & 4370 \\
\hline Vietnam & 2011 & $7,185,000$ & 3561 & $4.1(3.4 ; 4.9)$ & $1.2(0.8 ; 1.7)$ & 294585 & 86220 \\
\hline \multicolumn{2}{|c|}{ Total } & $18,243,000$ & 42,280 & $8.9(8.0 ; 9.9)$ & $2.0(1.7 ; 2.4)$ & $1,088,747$ & 279,862 \\
\hline
\end{tabular}

1 Figures obtained from state of world children reports; ${ }^{2} \mathrm{CI}=$ confidence interval; ${ }^{3}$ Burden is obtained by multiplying the total under 5 population by the weighted prevalence; ${ }^{4}$ wasted $=$ weight-for-height $<-2$ Z-score; ${ }^{5}$ Severely wasted = weight-for-height $<-3 \mathrm{Z}$-score; ${ }^{6}$ Lao PDR = Lao People's Democratic Republic. 


\section{Results}

\subsection{Characteristics of Survey Households, Mothers, and Children}

Table 1 describes the surveys analyzed for this paper. The surveys were conducted between 2011 and 2017 with the Vietnam survey being the oldest and the Thailand survey the most recent.

The number of households and mothers of children under five years old interviewed varied country by country with Vietnam having the smallest sample and Thailand the largest. Except for Thailand and Vietnam, two-thirds of the children included in the analysis were from rural areas. The 20 to 34 years age group dominated the sample of mothers interviewed in all the countries and represented $>60 \%$ of those interviewed in most of the countries. Overall, adolescent mothers represented less than $5 \%$ of the interviewed mothers. There was great variation in the level of maternal formal education. In Thailand and Vietnam most mothers attained secondary school or higher, while in the other countries over $60 \%$ had either primary or no formal education. Of the three countries for which data were available, Timor-Leste had the highest percentage of mothers with short stature and BMI $<18.5 \mathrm{~kg} \cdot \mathrm{m}^{-2}$. The sex ratio of surveyed children and their distribution across the different age groups was balanced in almost all the countries surveyed with each year interval contributing around $20 \%$ of the sample of children included in the analysis.

\subsection{Prevalence and Burden of Wasting}

Table 2 shows the pooled and country prevalence of wasting and severe wasting. The pooled prevalence of wasting was more than $5 \%$. For individual countries, this prevalence was above $5 \%$ in five of the six countries examined. Timor-Leste and Cambodia had a high prevalence while Lao PDR, Myanmar and Thailand had a medium prevalence. For severe wasting prevalence, the pooled prevalence of the six countries reached the emergency threshold of $2 \%$. The prevalence of wasting was above this threshold in Cambodia, Lao PDR and Timor-Leste and lower than this threshold in Myanmar, Thailand and Vietnam. In all the six countries, the number of children affected was high, giving a pooled figure of over 1 million under-five children affected by wasting, with close to 280,000 of them being severely wasted.

The prevalence of wasting across the age groups did not follow the same pattern across the countries included in the analysis (Figure 1). Cambodia, Myanmar, Thailand and Vietnam had the highest prevalence of wasting and severe wasting in the 0 to 5 months age group. In Lao PDR and Timor-Leste, the peak prevalence of wasting was highest among the 6-11 month and 12-23 month age groups respectively while for severe wasting the peak was in the 6-11 months group. In Cambodia, Lao PDR, Myanmar and Timor-Leste, multiple age groups had a prevalence of severe wasting above $2 \%$ with all six-age groups in Lao PDR having a prevalence above this cut-off. For Vietnam, no age group had a prevalence of severe wasting above $2 \%$.

When the age was dichotomized to $<24$ months and $\geq 4$ months, the pooled prevalence $(95 \% \mathrm{CI})$ of wasting for the 0 to 23 months age group and for the 24 to 59 months age group were $12.0(10.8-13.4 \%)$ and $6.3(5.5-7.2 \%)$, respectively $(p<0.001)$. For severe wasting, the prevalence was $2.9(2.3-3.6 \%)$ for the 0 to 23 months age group and $1.3(0.9-1.8 \%)$ for the 24 to 59 months age group $(p<0.001)$.

The prevalence of wasting and severe wasting observed in these age groups by country are presented in supplementary Figure S1. The difference between the two age groups was highly statistically significant $(p<0.001)$ in all the countries for both wasting and severe wasting. The relative risk of a child being wasted in the 0 to 23 months age group in comparison to a child in the 0 to 59 months varied across countries with the highest observed relative risk in Timor-Leste $(\mathrm{RR} 95 \% \mathrm{CI}=$ $2.13(1.88-2.41 \%)$ ) and the lowest in Thailand (RR 95\% CI = $1.24(1.05-1.45 \%)$ ). For severe wasting, Timor-Leste again had the highest relative risk (RR 95\% CI = $3.23(2.35-4.45 \%)$ ) while Vietnam had the lowest (RR 95\% CI = 1.15 (0.63-2.10\%). 


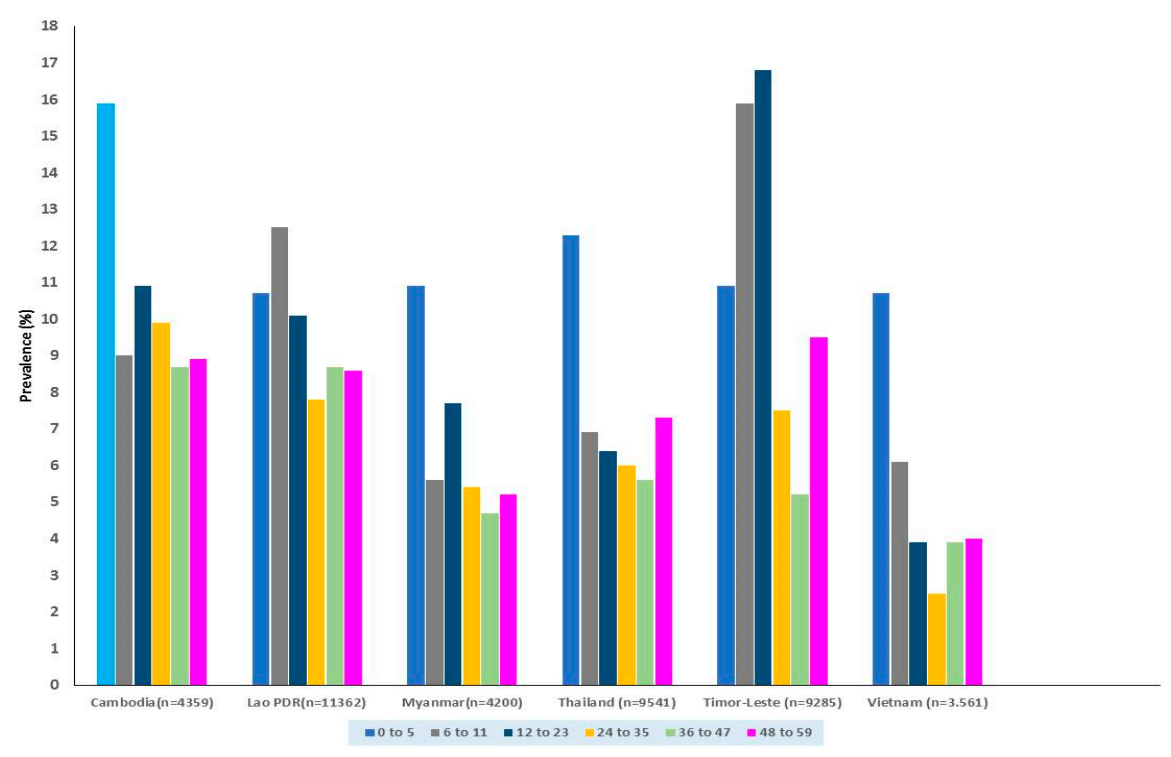

Figure 1. Prevalence of wasting in the different age groups by country.

The share of the total number of wasted children was equal for children in 0 to 23 months and 24 to 59 months age groups in the pooled analysis (Supplementary Figure S2). The country by country analysis showed that this was also the case for Cambodia, Myanmar and Vietnam. However, in Lao PDR and Thailand, the 0 to 23 months age group contributed more cases while the 24 to 59 months age contributed more cases in Timor-Leste (Supplementary Figure S2).

\subsection{Prevalence and Burden of the Concurrence of Wasting and Stunting}

The prevalence of concurrence of wasting and stunting varied widely from $1.05 \%$ to $5.30 \%$ and was the highest in Timor-Leste and lowest in Vietnam (Table 3). For the six countries, over 250,000 children were both wasted and stunted at the time of the surveys with the figure varying across countries and ranging from 10,070 to 75,443 children wasted and stunted (Table 3). Close to 18,000 children in the 0 to 59 months age group were experiencing both severe wasting and severe stunting at the time of the surveys with Thailand having the highest number and Lao PDR the lowest number.

There was a perfect and direct correlation (Spearman rho correlation rs $=1.0 ; p<0.001$ ) between the country's prevalence of wasting and concurrence of wasting and stunting (Figure 2).

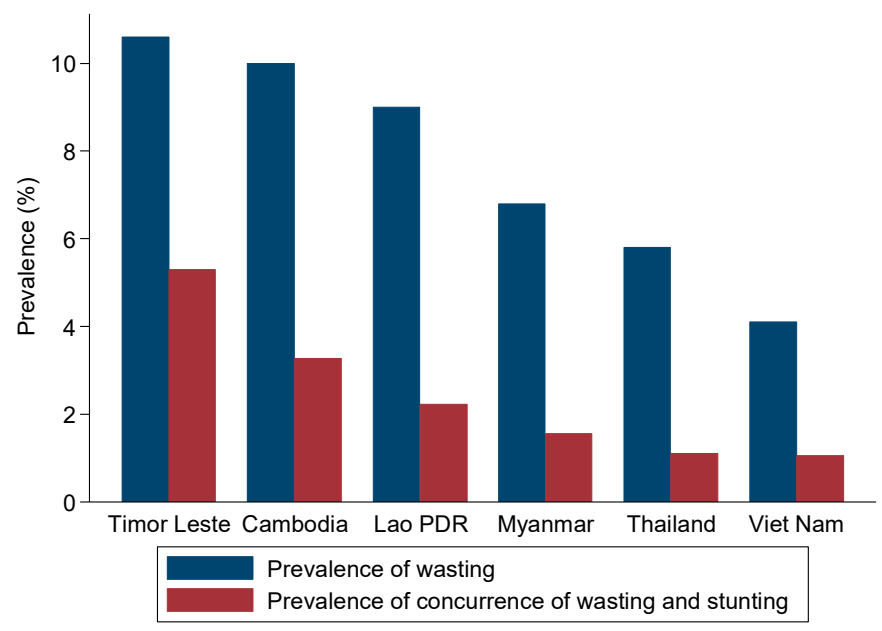

Figure 2. Prevalence of wasting and concurrence of wasting and stunting by country. 
Table 3. Prevalence and burden of wasting and stunting concurrence.

\begin{tabular}{|c|c|c|c|c|c|c|c|}
\hline \multirow{2}{*}{ Country } & \multirow{2}{*}{ Year of Survey } & \multirow{2}{*}{ Total Under 5 Population ${ }^{1}$} & \multirow{2}{*}{ Sample Size } & \multicolumn{2}{|c|}{ Prevalence $\left(95 \% \mathrm{CI}^{2}\right)$} & \multicolumn{2}{|c|}{ Burden ${ }^{3}$ (Number of Affected) } \\
\hline & & & & $\begin{array}{l}\text { Wasted \& } \\
\text { Stunted } 4\end{array}$ & $\begin{array}{l}\text { Severely Wasting \& } \\
\text { Severely Stunted }\end{array}$ & $\begin{array}{l}\text { Wasted \& } \\
\text { Stunted }\end{array}$ & $\begin{array}{l}\text { Severely Wasting \& } \\
\text { Severely Stunted } 5\end{array}$ \\
\hline Cambodia & 2014 & $1,742,000$ & 4336 & $3.27(2.74 ; 3.79)$ & $0.14(0.03 ; 0.25)$ & 56,963 & 2439 \\
\hline Lao PDR ${ }^{6}$ & 2017 & 777,000 & 11225 & $2.22(1.95 ; 2.49)$ & $0.17(0.09 ; 0.24)$ & 17,249 & 1321 \\
\hline Myanmar & 2015 & $4,565,000$ & 4186 & $1.56(1.18 ; 1.93)$ & $0.05(0.00 ; 0.12)$ & 71,214 & 2283 \\
\hline Thailand & $2015 / 16$ & $3,784,000$ & 9525 & $1.10(0.89 ; 1.31)$ & $0.14(0.06 ; 0.21)$ & 41,624 & 5298 \\
\hline Timor-Leste & 2013 & 190,000 & 9220 & $5.30(4.84 ; 5.76)$ & $0.31(0.19 ; 0.42)$ & 10,070 & 4370 \\
\hline Vietnam & 2011 & $7,185,000$ & 3552 & $1.05(0.71 ; 1.38)$ & $0.03(0.00 ; 0.09)$ & 75,443 & 2156 \\
\hline \multicolumn{2}{|c|}{ Total } & $18,243,000$ & 42,044 & $1.65(1.53 ; 1.78)$ & $0.13(0.09 ; 0.16)$ & 272,563 & 17867 \\
\hline
\end{tabular}

1 Figures obtained from state of world children reports; ${ }^{2} \mathrm{CI}=$ confidence interval; ${ }^{3}$ Burden is obtained by multiplying the total under 5 population by the weighted prevalence; ${ }^{4}$ Wasted \& stunted = children with both weight-for-height $<-2 \mathrm{Z}$-score and height-for-age $<-2{ }^{5}$ Severe wasted \& severely stunted $=$ children with both weight-for-height $<-3 \mathrm{Z}$-score and height-for-age $<-3$ Z-score; ${ }^{6}$ Lao PDR = Lao People's Democratic Republic. 
The concurrence was the lowest in the 0 to 5 month age group in four of the six countries (Figure 3). This prevalence shows a significant linear trend increasing as age increased in Cambodia $(p=0.001)$, Lao PDR $(p=0.035)$, in Myanmar $(p=0.016)$, Timor-Leste $(p=0.001)$ and Vietnam $(p=0.033)$ but not in Thailand ( $p=0.457)$. Despite the statistically significant linear trend, the highest prevalence was not always in the 48 to 59 age group. The peak prevalence for concurrence was observed in 36 to 47 months age group in Cambodia, in 12 to 23 months age group in Lao PDR, Thailand and Timor-Leste and in 48-59 months age group in Myanmar and Vietnam. When we excluded children below 12 months of age in the analysis, the direct linear relationship for the 12-59 age group was observed only for Timor-Leste $(p<0.001)$. The test of the linear trend was not significant for Cambodia $(p=0.920)$, Lao PDR $(p=0.115)$, Myanmar $(p=0.993)$, Thailand $(p=0.571)$ and Vietnam $(p=0.168)$.

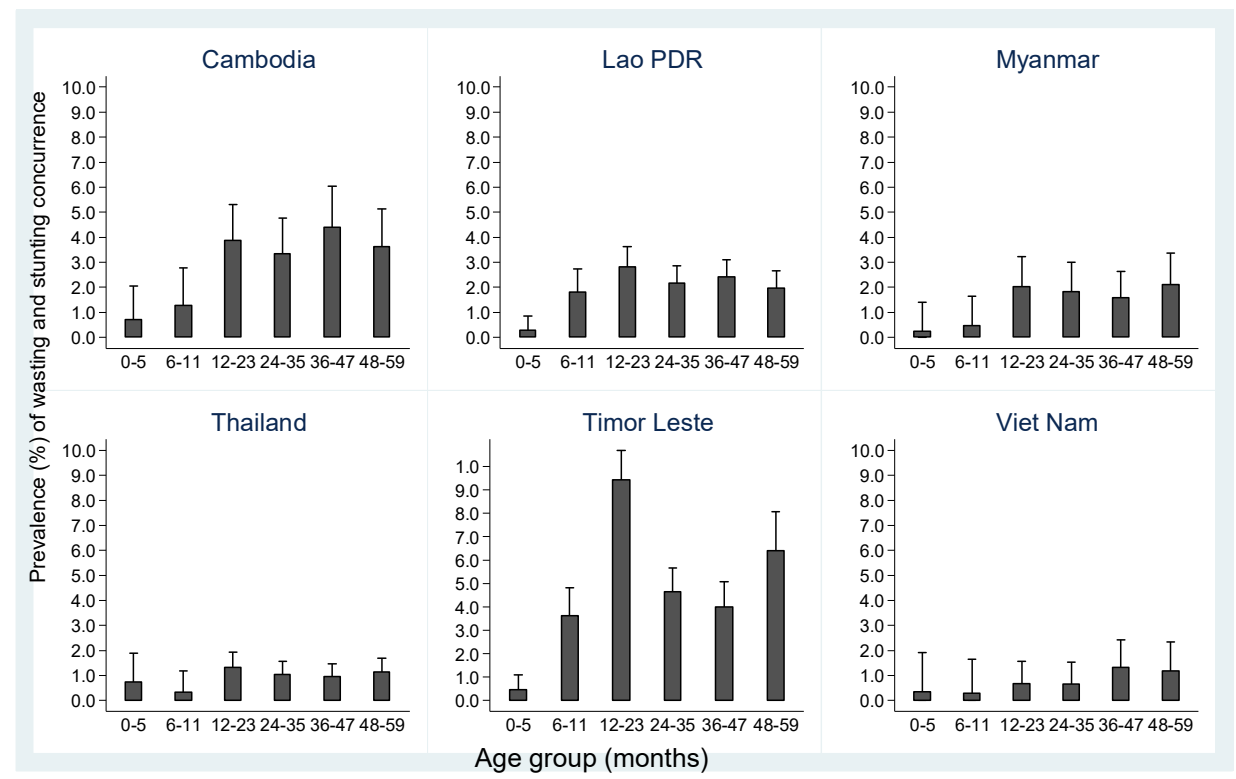

Figure 3. Prevalence concurrence of wasting and stunting by country and age groups.

The burden of concurrence was equally distributed across the under-five age groups for Cambodia, Lao PDR, Myanmar and Vietnam with each 12-month interval encountering approximately 20\% share of the burden (Supplementary Figure S3). For Thailand, the age group 0 to 11 months had a much lower share of concurrent wasting and stunting than the other four age groups and for Timor-Leste, the 0 to 11 month and 12 to 23 month age groups contributed $50 \%$ of the share of the burden while the 48 to 59 age group contributed only around 10\% (Supplementary Figure S3).

\subsection{Factors Associated with Risk of Wasting}

Table 4 presents the associations between wasting and the potential predictors tested in analyses that considered households, maternal and child characteristics separately. The household characteristic model showed that all the factors included in the analysis-place of residence, wealth index, number of people in the household source of drinking water were independently associated with risk of a child being wasted (Table 4). Comparing the richest and poorest wealth quintiles showed that children from the poorest quintile had a $25 \%$ increase in the risk of being wasted (OR $(95 \%)=1.25(1.10-1.43 \%)$; $p=0.001)$. 
Table 4. Predictors of wasting: univariate and separate multivariate multilevel regression analyses for the six countries.

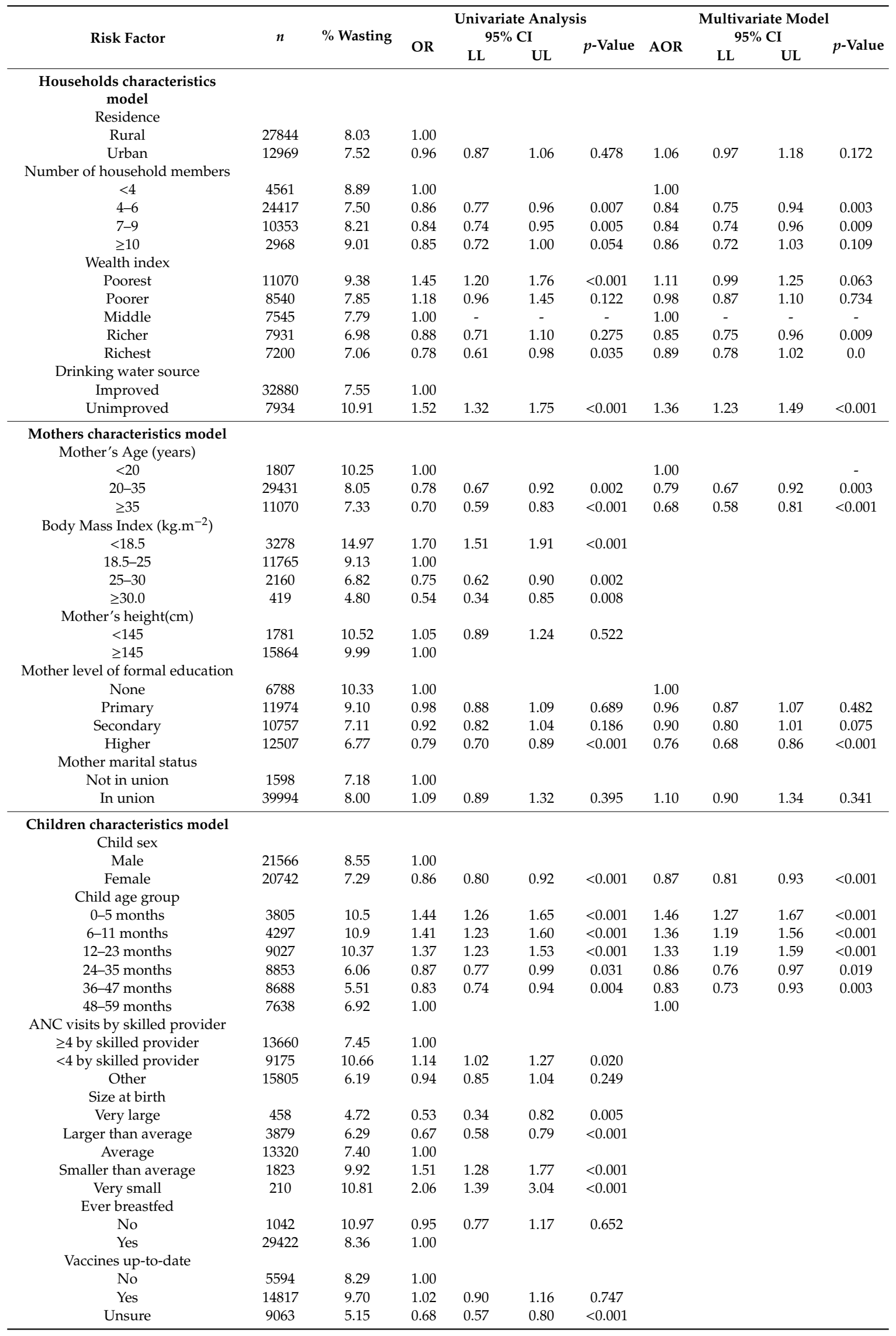


Table 4. Cont.

\begin{tabular}{|c|c|c|c|c|c|c|c|c|c|c|}
\hline \multirow{3}{*}{ Risk Factor } & \multirow{3}{*}{$n$} & \multirow{3}{*}{$\%$ Wasting } & \multicolumn{4}{|c|}{ Univariate Analysis } & \multirow{2}{*}{\multicolumn{4}{|c|}{$\begin{array}{l}\text { Multivariate Model } \\
95 \% \text { CI }\end{array}$}} \\
\hline & & & \multirow{2}{*}{ OR } & \multicolumn{2}{|c|}{$95 \%$ CI } & \multirow{2}{*}{$p$-Value } & \multirow{2}{*}{ AOR } & & & \\
\hline & & & & LL & UL & & & LL & UL & $p$-Value \\
\hline \multicolumn{11}{|l|}{ History of fever } \\
\hline No & 32922 & 7.38 & & & & & & & & \\
\hline Yes & 9372 & 9.78 & 1.26 & 1.16 & 1.36 & $<0.001$ & 1.21 & 1.11 & 1.32 & $<0.001$ \\
\hline History of diarrhoea & 42232 & & & & & & & & & \\
\hline No & 38111 & 7.65 & 1.00 & & & & & & & \\
\hline Yes & 4149 & 10.35 & 1.27 & 1.14 & 1.42 & $<0.001$ & 1.14 & 1.02 & 1.28 & 0.020 \\
\hline \multicolumn{11}{|l|}{ History of Cough } \\
\hline No & 12679 & 9.53 & & & & & & & & \\
\hline Yes & 5160 & 11.00 & 1.12 & 1.01 & 1.26 & 0.035 & & & & \\
\hline
\end{tabular}

${ }^{1} \mathrm{OR}=$ odds ratio; ${ }^{2} \mathrm{CI}=$ confidence interval; ${ }^{3} \mathrm{AOR}=$ adjusted odds ratio; ${ }^{4} \mathrm{LL}=$ lower limit; ${ }^{5} \mathrm{UL}=$ upper limit.

The mother's characteristics model identified mother's age and mother level of education as independent predictors of wasting among children (Table 4). Marital status was not an independent risk factor for wasting (Table 4). The mother characteristics model that included maternal BMI and height in addition to all the other variables revealed that the risk of being wasted for a child of a mother with a normal BMI ( $\geq 18 \mathrm{~kg} \cdot \mathrm{m}^{-2}$ and $\left.<25 \mathrm{~kg} \mathrm{~m}^{-2}\right)$ differed significantly with that of a mother with low BMI or high BMI. The risk of being wasted was $69 \%$ higher for a child of a mother with low BMI < $18.5 \mathrm{~kg} \mathrm{~m}^{-2}(\mathrm{AOR}(95 \% \mathrm{CI})=1.65(1.50-1.90 \%) ; p<0.001)$ when compared to a child of a mother with normal BMI. A child of a mother with higher BMI than the reference had a lower risk of being wasted $(\operatorname{AOR}(95 \% \mathrm{CI})=0.76(0.63 \%-0.91)) ; p=0.003)$ for a child of a mother with $\mathrm{BMI} \geq 25 \mathrm{~kg} \cdot \mathrm{m}^{-2}$ and $\mathrm{BMI}<$ $30 \mathrm{~kg} \mathrm{~m}^{-2}$, and AOR $(95 \% \mathrm{CI})=0.55(0.34-0.87 \%) ; p=0.0 .011$ for a child of a mother with BMI $\geq 30 \mathrm{~kg}$ $\mathrm{m}^{-2}$. Maternal short stature, height $145 \mathrm{~cm}$ was not associated with a higher risk of wasting (AOR $(95 \% \mathrm{CI})=0.97(0.83-1.15 \%) ; p=0.767)$. In this model, including only data from Cambodia, Myanmar and Timor-Leste, mother's level of education was no longer a predictor of child wasting, but mother's age remained (data not shown).

The child characteristics model identified child's sex, age, history of fever and or diarrhea as independent predictors of wasting (Table 4). Size at birth and quality of antenatal care were also included in the model for three countries and were independently associated with the presence of wasting. The risk of being wasted was significantly higher if the child was reported to have been very small at birth $($ AOR $(95 \%)=2.01(1.24-3.27 \%) ; p=0.004)$ or smaller $($ AOR $(95 \%)=1.56(1.28-1.90 \%)$; $p<0.001)$ than average at birth. On the contrary, the risk of being wasted was reduced if the child was large $($ AOR $(95 \%)=0.69(0.57-0.82 \%) ; p<0.001)$ or very large $($ AOR $(95 \%)=0.54(0.33-0.90) ; p=0.017)$ compared to the average at birth according to mother's recall. The variables of adjustment for this model were age, sex, vaccination status, antenatal care, history of fever and history of diarrhea.

Interestingly, while children of the poorest households had an increased risk of being wasted compared to those from households of the average wealth category in the household characteristic model, there was no difference in the combined model between these two categories (Table 4). Another important change in association when comparing the combined and separate models is that in the mother characteristic model risk of wasting was lower among children with mothers over 20, compared to mothers who were less than 20 , but this difference was not observed in the combined model.

In contrast, the differences between the average wealth category and the wealthiest categories that were not significant in the separate model became significant in the combined model with children in the wealthiest categories having an increased risk of wasting (Table 4). The combined model showed an association between higher levels of formal education and lower wasting in chidren, while child history of fever or diarrhea increased the likelihood of wasting even after controlling for the selected household's and mother's characteristics (Table 4).

\section{Discussion}

The analysis presented in this paper, based on nationally representative data of six countries of Southeast Asia, shows that the prevalence of wasting is of medium public health importance in 
the region. However, translating prevalence into an absolute number of children under five that are wasted highlights that wasting should be considered a serious public health problem for the region. The analysis also revealed that the prevalence of concurrent stunting and wasting is relatively low at $1.65 \%$, but the overall number of children affected was more than 250,000 in the six countries alone. These findings call for increased attention to this health condition, given the associated higher risk of death. The analysis also showed that the age groups at which prevalence of wasting peaks varies across countries in the region, four countries showed a peak prevalence of wasting in children 0 to 5 months and two countries had the highest prevalence among children 6-23 months. Finally, the combined multivariate modelling of households, maternal and child variables identified antenatal care by skilled staff, maternal BMI and child size at birth as independent predictors of wasting, mediated through prenatal growth restriction, the source of drinking water, and history of recent episode of fever and diarrhea, that operate through postnatal growth deterioration and place of residence, wealth level of the household, mother's formal education level and child's sex.

\subsection{Prevalence and Burden of Wasting}

Our analysis has demonstrated that a significant proportion of under five children in the countries surveyed, are still suffering from wasting despite the rapid economic growth and the tremendous improvement of food availability [36,39]. Indeed, the pooled prevalence of $8.9 \%$ is 12 -fold higher than the $0.7 \%$ for high-income countries [28]; and the prevalence is over $10 \%$ in two of the six countries examined. The total number of children affected by wasting is over one million, which is more than the total population of under-five children of Lao PDR and Timor-Leste combined. These findings justify classifying wasting as serious public health problem in the Southeast Asia region [28,40]. Furthermore, positioning wasting as a serious public health concern across the entire Southeast Asia region and tackling it is likely to yield global benefits as the region contributes a significant share to the global burden of wasting. Our analysis suggests that the six countries examined contribute approximately $2 \%$ of the global wasting burden, and it is estimated that the entire Southeast Asia region contributes to around 5.1 million cases or $10 \%$ of the global wasting burden [28]. This contribution, when added to that of South Asia, an equally densely populated region, in which wasting prevalence was between $9.5 \%$ and $21.0 \%$ in an analysis carried out recently by Harding et al., makes Asia the continent with the largest share of the global under five children wasting burden [41].

Our analysis has also shown that using prevalence figures for wasting solely to determine the public health importance of wasting may be misleading, especially in countries with a large population. For example, in Vietnam, using a wasting prevalence of $4.1 \%$, wasting would be considered of low public health importance. However, the country has a higher absolute number of affected children than both Cambodia and Timor-Leste, which have wasting prevalence of $10.0 \%$ and $10.6 \%$, respectively. Similar findings have been reported in seven countries of Southeast Asia, including four of the countries we analyzed, namely Cambodia, Lao PDR, Timor-Leste, Vietnam and Myanmar, Indonesia and the Philippines [42]. Consequently, the prevalence of wasting should always be contextualized. Many experts recommend using national or sub-national population size and national health system capacity to cope with the caseload, in addition to prevalence and aggravating factors for wasting in considering the classification and design of interventions to address childhood wasting.

\subsection{The Concurrence of Wasting and Stunting}

Stunting is also a serious public health problem in Southeast Asia region, with most countries having a stunting prevalence of above $30 \%$ [42-44] and despite the coexistence of wasting and stunting in the region, no attention has been paid to the concurrence of both. Our analysis shows that the prevalence of concurrent wasting and stunting is low for the six countries examined, with a pooled prevalence of $1.65 \%$. This prevalence was lower than the global prevalence of $3.0 \%$ reported by Khara et al. based on an analysis of 84 DHS survey including Cambodia, Lao PDR, Thailand and Timor-Leste [45]. It was also much lower than the pooled unweighted prevalence of $6.11 \%$ reported by 
Harding et al. for six countries in the neighboring South Asia region (Afghanistan, Bangladesh, India, Maldives, Nepal and Pakistan), confirming that the two Asian regions have different undernutrition profiles [41]. However, this unweighted prevalence for South Asia must be considered with caution as India provided $89 \%$ of the sample analyzed and alone had a concurrence prevalence of $6.62 \%$ [41].

As with the prevalence of wasting, interpretation of this low concurrence of wasting and stunting prevalence should take into account the population size of Southeast Asia. Indeed, the prevalence of $1.65 \%$ obtained in our analysis translates into a quarter-million of under five children affected. These children need particular attention as studies have shown that they are at high risk of dying even when they are moderately wasted $[21,46]$. Thus, the approach for screening and selecting children for wasting interventions should be adjusted to ensure children with concurrent wasting and stunting are able to access the most effective treatment for their condition. Some authors suggest to treat them as severely wasted children with the addition of weight-for-age screening criteria, where MUAC alone is used as eligibility for therapeutic feeding programs [21,47]. According to emerging evidence, the addition of a weight-for-age criterion allows the identification of concurrently wasted and stunted children and wasted children at increased risk of death that are not identified by current MUAC criteria [47].

Lastly, the observed low prevalence of concurrent stunting and wasting at less than $2 \%$ has important policy and programmatic implications for the region. It suggests that in Southeast Asia region, the great majority of wasted children will not be reached by programs designed to combat stunting alone and those that only use height/length-for-age criteria for the selection of beneficiaries. Both conditions should be targeted specifically, although programmatically interventions can be combined to maximize the impact. Indeed, although limited, there is evidence that stunted and wasted children respond well to treatment of wasting and that recovery from wasting may be followed by linear growth acceleration $[12,48]$.

Our analysis shows that in most countries reviewed the prevalence of concurrence was lower among infants below 12 months of age, similar to the observation by Khara et al. who observed increased concurrence prevalence after 12 months of age [45]. These authors concluded that the increase in concurrence after 12 months was due to the high prevalence of both wasting and stunting in their study population. This explanation does not hold for our analysis as the increase in concurrence of wasting and stunting was also observed in countries where wasting prevalence was the highest amongst children less than 12 months of age. Alternative explanations are a rapid increase in the prevalence of stunting and an interrelationship between the two forms of undernutrition with stunting increasing risk of wasting occurrence and vice versa. The variation and degree of this interrelation may also explain the global and country level differences identified in wasting and stunting prevalence [21,45]. Unfortunately, the cross-sectional nature of the surveys included in our analysis do not allow for the verification of this hypothesis. This hypothesis should be verified in future appropriate longitudinal studies.

\subsection{Risk Factors for Wasting}

Our analysis has shown that the source of drinking water had the strongest association with wasting in the full model, including all the available variables and data from all the six countries. This finding is consistent with the literature, including studies conducted in a different countries in Asia $[1,49,50]$. The possible pathway is through increased frequency of diarrhea and intestinal parasites which contribute to the development of Environmental Enteric dysfunction syndrome [51-54]. Interestingly, diarrhea was also an independent predictor of wasting in this model. These findings advocate for the prioritization of programs aimed at improving access to clean water, despite the current weakness of evidence around prevention of undernutrition through WASH or combination of WASH and food supplementation interventions [50,55-57].

Several maternal factors have consistently been identified as factors associated with increased risk of wasting in under-five children. Younger maternal age, height below $145 \mathrm{~cm}$, low level of education and low BMI has been linked with increased risk of wasting in several studies [35,41,58-63]. In our 
analysis, however, only BMI was associated with risk of wasting. There was no association between maternal age and maternal height and risk of child wasting. For the level of mother's education, only those with more than secondary education had a lower risk of having a wasted child when compared to those without formal education. Low Maternal BMI is among the key determinants of low birth weight (LBW), also known as small size at birth. LBW prevalence is undoubtedly responsible for most of the observed association between low maternal BMI and wasting, although maternal BMI might have changed since the child was born [64,65]. The impact of LBW prevalence on wasting prevalence is evident in the four countries that had the highest wasting prevalence among infants 0 to 5 months old. This epidemiological profile is observed in many Asian countries [34,41]. Thus, strategies to tackle wasting in the Southeast Asia region must include prevention of LBW, including the prevention of malnutrition among all women of reproductive age (WRA) and adolescents. Targeting WRA with nutrition and health interventions could also break the cycle of undernutrition as women born LBW or who experience undernutrition during childhood have increased the chance of having a LBW infant or undernourished child [41,66-68]. Furthermore, preventing or treating undernutrition of WRA is likely to contribute to the reduction of the prevalence of non-communicable chronic diseases [69-73].

Size at birth was also an independent predictor of child wasting in a model including mothers' BMI indicating that both variables had a direct and independent influence on the risk of wasting of under five children in the three countries that provided data for this analysis. A similar result has been reported by many other authors $[41,74]$. This suggest a difference in postnatal growth between LBW and normal birth weight infants. in $[42,75,76]$. Thus, efforts to reduce the prevalence of wasting among children under five should also include postnatal interventions aiming at improving the growth of LBW during early infancy. The World Health Organization (WHO) recommends exclusive breastfeeding up to six months of age and the provision of counselling to improve complementary feeding practices e $[1,77]$. Some nutrition experts are now advocating for complementing these mostly preventive interventions with community-based interventions that are able to reverse wasting among the children below six months of age [74,78]. Unfortunately, to date, there is no validated treatment approach for this during early infancy.

Our analysis showed persistent wasting prevalence of $>5 \%$ among children $24-35$ months in comparison to the reference group. This shows that that post-natal factors contribute to the occurrence of wasting in the six countries, and that these age groups also require policy attention. This view is also backed by the fact that $50 \%$ of the absolute number of wasted children were from the age group above 24 months.

While wasting prevalence is below $5 \%$ in children $0-23$ months, the increase in risk of wasting is greater than $50 \%$ for all age categories less than 24 months, when compared to the 48-59 month group. This finding underscores the higher vulnerability of children below 24 months of age to wasting. In line with the now widely accepted concept of 1000 day window of opportunity, children in the $0-23$ months age group should be prioritized for all nutrition interventions [1].

A surprising finding from our analysis is the higher risk of wasting among children from urban households than those from rural households. Indeed, most studies have reported that rural children have a higher risk of becoming wasted than urban children [36,41]. Further investigations are needed to confirm and understand this relationship. However, the possibility of the shift towards more wasting in urban settings of low and middle-income countries was predicted in the UNICEF publication Innocenti Digest number 10 in 2002 [79]. Under five children living in informal settlements in large cities are often exposed to very precarious conditions that can lead to poor health status, including poor nutrition status $[79,80]$. The presence of such informal settlements should be a trigger for including urban setting in all strategies to tackle undernutrition.

The other variables associated with child wasting in our analysis are child sex, a recent episode of fever and a recent episode of diarrhea. For all these variables, our findings show a lower likelihood of being wasted for girls than boys and a higher likelihood of being wasted for those with a history of a recent episode of fever or diarrhea, consistent with the existing literature [1,41,42,81]. For fever and 
diarrhea, the mechanisms are well understood, and the interventions of known effectiveness are well integrated into the health system and implemented at scale in most countries. For the sex association with wasting, further studies are needed to understand this association. Some experts suggest that it could be an artefact due to the difference in new WHO growth standards and the median growth trajectories of boys. Other experts speculate that this could be due to a difference in physical activity.

The current global renewed interest in tacking undernutrition including wasting has not been sufficiently embraced by governments and other actors in the Southeast Asia region, yet it remains a serious public health problem $[82,83]$. Interventions to address wasting are unfortunately not currently accessible to many of the vulnerable children in the region and where offered the coverage is very limited [27]. Many Asian nutrition experts believe that prenatal factors, including poor maternal nutrition and health during the preconception period and pregnancy, are the main determinants of wasting in children under five. This is because the prevalence of wasting peaks in the $0-5$ months age group in some Asian countries, compared to after infancy which is common in other settings [34,84]. The peak in prevalence of wasting in the 0 to 5 months group has recently emerged as a key indicator to decide whether the determinants of wasting in a given country are predominantly prenatal or postnatal $[34,41,60]$. In our analysis, the age distribution pattern across the different age groups was not consistent across all the countries. In Cambodia, Myanmar, Thailand and Vietnam wasting was highest in the 0-5 months age group as described in de Wagt et al. paper, but not in Lao PDR and Timor-Leste [34]. Moreover, in the four countries that had a higher prevalence of wasting in the 0 to 5 months group, and had a similar profile to that observed in South Asia, the prevalence of wasting remained above $5 \%$ in all the age groups up to the 48 to 59 months age group [34,41]. This can hardly be explained by the effect of prenatal factors alone [84]. Furthermore, the low overlap between stunting and wasting observed in this analysis also indicates that post-natal factors play an important role in the occurrence of wasting in the examined countries.

Lastly, the wasting prevalence of $8.9 \%$ we observed was encountered despite the rapid economic growth and food production increase experienced in the Southeast Asia region in recent years. This observation confirms that of several authors who previously reported that national-level indicators of economic situation and agriculture outputs can be misleading. An increase in macro-economic indicators such as the per capita gross domestic product may not have an immediate effect on nutrition indicators and the effect may remain limited years after the improvement of the income and food security national figures [39].

\subsection{Strengths and Limitations}

The results presented and discussed in this paper should be interpreted taking into account the strengths and limitations of our study. The main strengths of this study are the use of data from the most methodologically robust national surveys and the use of a multicounty dataset combining data of six countries in the Southeast Asia region. However, we cannot assume that these countries are representative of the entire region, given that they were selected according accessibility of data. Another strength is that we used the most recent surveys available at the time of the analysis.

Our study had several limitations. The first limitation arises from our study design (cross sectional data) that does not allow to distinguish causality from association. Neither is it possible to distinguish direction of association. Second, we acknowledge that our datasets were not designed for looking at different age groups and data is only representative of the under-five age group. All analysis by age group should be looked at with caution. Third, is the unavailability of data on the head of the household characteristics, household food security level, sanitation type, mothers' principal source of income, child exclusive breastfeeding history and the child dietary diversity score. The high proportion of missing data for some key variables such as size at birth, mother's height and BMI and child's history of cough is also an important limitation. Four, is the variation in years of surveys. Data of the oldest survey was collected in 2011 and the most recent in 2017. Despite these limitations, we believe 
that the findings are informative and should serve as a basis for updating strategies to combat wasting in examined countries and all countries of the region facing this serious public health problem.

\section{Conclusions}

Wasting remains a serious public health problem in many countries of the Southeast Asia region. The global target to reduce the prevalence of wasting to below five per cent by 2025 may not be reached unless the policy environment is significantly improved to enable the scale-up of preventive and curative interventions with high impact on wasting incidence and nutrition outcomes. For a rapid decline in the prevalence of wasting, women of reproductive age (WRA) including adolescents, and children under five need to be targeted simultaneously with preventive and treatment approaches as both prenatal and postnatal factors are contributing to the burden of wasting in the region. Such integrated programming is likely to have an impact that goes beyond the control of wasting by reducing stunting and by contributing to the prevention of the looming non-communicable diseases pandemic. Our findings suggest that deliberate efforts must be made to address wasting despite the rapid economic growth and improvement in food security. Our recommendation is for countries in the region and their partners to immediately scale-up\# interventions with proven efficacy to address wasting in children. Further studies should be undertaken to assess the causal pathways of wasting and propose the most appropriate strategies that support the elimination of wasting and other forms of malnutrition in the region.

Supplementary Materials: The following are available online at http://www.mdpi.com/2072-6643/12/2/559/s1, Figure S1: Contribution of the 0 to23 months and 24 to 59 months age groups to wasting caseload; Figure S2: Distribution of the burden of wasting and concurrence across age group 12-months interval by country.

Author Contributions: Conceptualization, M.M. and S.F.; methodology, S.F. and P.B.; formal analysis, S.F. and P.B.; data curation, M.R. and S.F.; writing_-original draft preparation, P.B.; writing-review and editing, M.M.; visualization, P.B. and M.M.; supervision, M.M. All authors have read and agreed to the published version of the manuscript.

Funding: This research received no external funding.

Acknowledgments: The authors thank DHS and MICS for granting the access to the datasets and allowing the secondary analysis of the data. The authors also thank all the countries included for their collaboration. They also acknowledge all children and women surveyed. Finally, thanks to Alexandra Rutishauser-Perera, Action Against Hunger (UK) for providing administrative and technical support for this study.

Conflicts of Interest: The authors declare no conflict of interest

\section{References}

1. Black, R.E.; Victora, C.G.; Walker, S.P.; Bhutta, Z.A.; Christian, P.; de Onis, M.; Ezzati, M.; Grantham-McGregor, S.; Katz, J.; Martorell, R.; et al. Maternal and child undernutrition and overweight in low-income and middle-income countries. Lancet 2013, 382, 427-451. [CrossRef]

2. Galler, J.R.; Bryce, C.P.; Zichlin, M.L.; Fitzmaurice, G.; Eaglesfield, G.D.; Waber, D.P. Infant malnutrition is associated with persisting attention deficits in middle adulthood. J. Nutr. 2012, 142, 788-794. [CrossRef]

3. Jukes, M. The long-term impact of preschool health and nutrition on education. Food Nutr. Bull. 2005, 26 (Suppl. S2), S193-S201. [CrossRef]

4. Grantham-McGregor, S. A review of studies of the effect of severe malnutrition on mental development. J. Nutr. 1995, 125 (Suppl. S8), 2233-2238. [CrossRef]

5. Black, R.E.; Bhutta, Z.A.; Alderman, H.; Ruel, M.; Gillespie, S.; Haddad, L. Maternal and child nutrition-Authors' reply. Lancet 2013, 382, 1551-1552. [CrossRef]

6. Galler, J.R.; Bryce, C.; Waber, D.P.; Zichlin, M.L.; Fitzmaurice, G.M.; Eaglesfield, D. Socioeconomic outcomes in adults malnourished in the first year of life: A 40-year study. Pediatrics 2012, 130, e1-e7. [CrossRef] [PubMed]

7. Bowie, M.D.; Moodie, A.D.; Mann, M.D.; Hansen, J.D. A prospective 15-year follow-up study of kwashiorkor patients. Part I. Physical growth and development. S. Afr. Med. J. 1980, 58, 671-676. [PubMed] 
8. Chandra, R.K.; Chakraburty, S.; Chandra, S. Malnutrition, humoral immunity and infection. Indian J. Pediatr. 1976, 43, 159-171. [CrossRef] [PubMed]

9. Tomkins, A.; Watson, F. Malnutrition and infection: A review. Nutrition policy discussion paper No. 5; WHO: Geneva, Switzerland, 1989.

10. Victora, C.G.; Adair, L.; Fall, C.; Hallal, P.C.; Martorell, R.; Richter, L.; Sachdev, H.S. Maternal and child undernutrition: Consequences for adult health and human capital. Lancet 2008, 371, 340-357. [CrossRef]

11. Collins, S.; Dent, N.; Binns, P.; Bahwere, P.; Sadler, K.; Hallam, A. Management of severe acute malnutrition in children. Lancet 2006, 368, 1992-2000. [CrossRef]

12. Isanaka, S.; Hitchings, M.D.T.; Berthe, F.; Briend, A.; Grais, R.F. Linear growth faltering and the role of weight attainment: Prospective analysis of young children recovering from severe wasting in Niger. Matern. Child Nutr. 2019, 15, e12817. [CrossRef] [PubMed]

13. Brown, K.H.; Black, R.E.; Becker, S. Seasonal changes in nutritional status and the prevalence of malnutrition in a longitudinal study of young children in rural Bangladesh. Am. J. Clin. Nutr. 1982, 36, 303-313. [CrossRef] [PubMed]

14. Uauy, R.; Desjeux, J.F.; Ahmed, T.; Hossain, M.; Brewster, D.; Forbes, D.; Caton, H.; Kleinman, R.E. Global efforts to address severe acute malnutrition. J. Pediatric Gastroenterol. Nutr. 2012, 55, 476-481. [CrossRef] [PubMed]

15. Olofin, I.; McDonald, C.M.; Ezzati, M.; Flaxman, S.; Black, R.E.; Fawzi, W.W.; Caulfield, L.E.; Danaei, G. Associations of suboptimal growth with all-cause and cause-specific mortality in children underfive years: A pooled analysis of ten prospective studies. PLOS ONE 2013, 8, e64636. [CrossRef] [PubMed]

16. Black, R.E.; Allen, L.H.; Bhutta, Z.A.; Caulfield, L.E.; de Onis, M.; Ezzati, M.; Mathers, C.; Rivera, J. Maternal and child undernutrition: Global and regional exposures and health consequences. Lancet 2008, 371, $243-260$. [CrossRef]

17. Owino, V.O.; Murphy-Alford, A.J.; Kerac, M.; Bahwere, P.; Friis, H.; Berkley, J.A.; Jackson, A.A. Measuring growth and medium- and longer-term outcomes in malnourished children. Matern. Child Nutr. 2019, 15, e12790. [CrossRef]

18. Tennant, I.A.; Barnett, A.T.; Thompson, D.S.; Kips, J.; Boyne, M.S.; Chung, E.E.; Chung, A.P.; Osmond, C.; Hanson, M.A.; Gluckman, P.D.; et al. Impaired cardiovascular structure and function in adult survivors of severe acute malnutrition. Hypertension 2014, 64, 664-671. [CrossRef]

19. Wang, N.; Chen, Y.; Ning, Z.; Li, Q.; Han, B.; Zhu, C.; Chen, Y.; Xia, F.; Jiang, B.; Wang, B.; et al. Exposure to Famine in Early Life and Nonalcoholic Fatty Liver Disease in Adulthood. J. Clin. Endocrinol. Metab. 2016, 101, 2218-2225. [CrossRef]

20. Wang, N.; Wang, X.; Li, Q.; Han, B.; Chen, Y.; Zhu, C.; Chen, Y.; Lin, D.; Wang, B.; Jensen, M.D.; et al. The famine exposure in early life and metabolic syndrome in adulthood. Clin. Nutr. 2017, 36, 253-259. [CrossRef]

21. Myatt, M.; Khara, T.; Schoenbuchner, S.; Pietzsch, S.; Dolan, C.; Lelijveld, N.; Briend, A. Children who are both wasted and stunted are also underweight and have a high risk of death: A descriptive epidemiology of multiple anthropometric deficits using data from 51 countries. Arch. Public Health 2018, 76, 28. [CrossRef]

22. WHO. Management of Severe Malnutrition: A Manual for Physicians and other Senior Health Workers; WHO: Geneva, Switzerland, 1999.

23. WHO. Guideline: Updates on the Management of Severe Acute Malnutrition in Infants and Children; World Health Organization: Geneva, Switzerland, 2013.

24. WHO; WFP. UNICEF \& UNSCN: Joint Statement on the Community-Based Management of Severe Malnutrition in Children; WHO: Geneva, Switzerland, 2007.

25. Park, S.E.; Kim, S.; Ouma, C.; Loha, M.; Wierzba, T.F.; Beck, N.S. Community management of acute malnutrition in the developing world. Pediatr. Gastroenterol. Hepatol. Nutr. 2012, 15, 210-219. [CrossRef] [PubMed]

26. Briend, A.; Collins, S. Therapeutic nutrition for children with severe acute malnutrition summary of African experience. Indian Pediatr. 2010, 47, 655-659. [CrossRef] [PubMed]

27. Ahmed, T.; Hossain, M.; Mahfuz, M.; Choudhury, N.; Hossain, M.M.; Bhandari, N.; Lin, M.M.; Joshi, P.C.; Angdembe, M.R.; Wickramasinghe, V.P. Severe acute malnutrition in Asia. Food Nutr. Bull. 2014, 35 (Suppl. S1), 14-26. [CrossRef] 
28. UNICEF; World Health Organization; World Bank. Levels and Trends in Child Malnutrition: Key Findings of the 2016 Edition; UNICEF: New York, NY, USA; WHO: Geneva, Switzerland; World Bank: Washington, DC, USA, 2018.

29. Burza, S.; Mahajan, R.; Marino, E.; Sunyoto, T.; Shandilya, C.; Tabrez, M.; Kumar, K.; Jha, A.; Mathew, P.; Salse, N.; et al. Seasonal effect and long-term nutritional status following exit from a Community-Based Management of Severe Acute Malnutrition program in Bihar, India. Eur. J. Clin. Nutr. 2016, 70, 437-444. [CrossRef] [PubMed]

30. Burza, S.; Mahajan, R.; Marino, E.; Sunyoto, T.; Shandilya, C.; Tabrez, M.; Kumari, K.; Mathew, P.; Jha, A.; Salse, N.; et al. Community-based management of severe acute malnutrition in India: New evidence from Bihar. Am. J. Clin. Nutr. 2015, 101, 847-859. [CrossRef]

31. Puett, C.; Sadler, K.; Alderman, H.; Coates, J.; Fiedler, J.L.; Myatt, M. Cost-effectiveness of the community-based management of severe acute malnutrition by community health workers in southern Bangladesh. Health Policy Plan. 2012, 28, 386-399. [CrossRef] [PubMed]

32. Sadler, K.; Puett, C.; Mothabbir, G.; Myatt, M. Community Case Management of Severe Acute Malnutrition in Southern Bangladesh (Tufts University/Save the Children/GAIN/Pepsico); Tufts University: Boston, MA, USA, 2013.

33. Harris, S.; Jack, S. Home-based treatment of acute malnutrition in Cambodian urban poor communities. Food Nutr. Bull. 2011, 32, 333-339. [CrossRef]

34. de Wagt, A.; Rogers, E.; Kumar, P.; Daniel, A.; Torlesse, H.; Guerrero, S. Continuum of care for children with wasting in India: Opportunities for an integrated approach. Field Exch. 2019, 82, 82-90.

35. Vollmer, S.; Bommer, C.; Krishna, A.; Harttgen, K.; Subramanian, S.V. The association of parental education with childhood undernutrition in low- and middle-income countries: Comparing the role of paternal and maternal education. Int. J. Epidemiol. 2017, 46, 312-323. [CrossRef]

36. Pasricha, S.R.; Biggs, B.A. Undernutrition among children in South and South-East Asia. J. Paediatr. Child Health 2010, 46, 497-503. [CrossRef]

37. Lakshmi, S.; Metcalf, B.; Joglekar, C.; Yajnik, C.S.; Fall, C.H.; Wilkin, T.J. Differences in body composition and metabolic status between white U.K. and Asian Indian children (EarlyBird 24 and the Pune Maternal Nutrition Study). Pediatr. Obes. 2012, 7, 347-354. [CrossRef] [PubMed]

38. Klasen, S. Malnourished and Surviving in South Asia, Better Nourished and Dying Young in Africa: What Can Explain This Puzzle? Universitätsbibliothek der Ludwig-Maximilians-Universität: Munich, German, 2000.

39. Vollmer, S.; Harttgen, K.; Subramanyam, M.A.; Finlay, J.; Klasen, S.; Subramanian, S.V. Association between economic growth and early childhood undernutrition: Evidence from 121 Demographic and Health Surveys from 36 low-income and middle-income countries. Lancet Glob. Health 2014, 2, e225-e234. [CrossRef]

40. de Onis, M.; Borghi, E.; Arimond, M.; Webb, P.; Croft, T.; Saha, K.; De-Regil, L.M.; Thuita, F.; Heidkamp, R.; Krasevec, J.; et al. Prevalence thresholds for wasting, overweight and stunting in children under 5 years. Public Health Nutr. 2019, 22, 175-179. [CrossRef] [PubMed]

41. Harding, K.L.; Aguayo, V.M.; Webb, P. Factors associated with wasting among children underfive years old in South Asia: Implications for action. PLoS ONE 2018, 13, e0198749. [CrossRef] [PubMed]

42. Chaparro, C.; Oot, L.; Sethuraman, K. Overview of the Nutrition Situation in Seven Countries in Southeast Asia; FHI: Washington, DC, USA, 2014.

43. Bloem, M.W.; de Pee, S.; Hop Le, T.; Khan, N.C.; Laillou, A.; Minarto; Moench-Pfanner, R.; Soekarjo, D.; Soekirman; Solon, J.A.; et al. Key strategies to further reduce stunting in Southeast Asia: Lessons from the ASEAN countries workshop. Food Nutr. Bull. 2013, 34 (Suppl. S2), S8-S16. [CrossRef] [PubMed]

44. Khara, T.; Mwangome, M.; Ngari, M.; Dolan, C. Children concurrently wasted and stunted: A meta-analysis of prevalence data of children 6-59 months from 84 countries. Matern. Child Nutr. 2018, 14, e12516. [CrossRef] [PubMed]

45. McDonald, C.M.; Olofin, I.; Flaxman, S.; Fawzi, W.W.; Spiegelman, D.; Caulfield, L.E.; Black, R.E.; Ezzati, M.; Danaei, G. The effect of multiple anthropometric deficits on child mortality: Meta-analysis of individual data in 10 prospective studies from developing countries. Am. J. Clin. Nutr. 2013, 97, 896-901. [CrossRef]

46. Myatt, M.; Khara, T.; Dolan, C.; Garenne, M.; Briend, A. Improving screening for malnourished children at high risk of death: A study of children aged 6-59 months in rural Senegal. Public Health Nutr. 2019, 22, 862-871. [CrossRef] 
47. Briend, A.; Khara, T.; Dolan, C. Wasting and stunting-Similarities and differences: Policy and programmatic implications. Food Nutr. Bull. 2015, 36 (Suppl. S1), S15-S23. [CrossRef]

48. Bhutta, Z.A.; Das, J.K.; Rizvi, A.; Gaffey, M.F.; Walker, N.; Horton, S.; Webb, P.; Lartey, A.; Black, R.E.; Lancet Nutrition Interventions Review Group; et al. Evidence-based interventions for improvement of maternal and child nutrition: What can be done and at what cost? Lancet 2013, 382, 452-477. [CrossRef]

49. de Pee, S.; Grais, R.; Fenn, B.; Brown, R.; Briend, A.; Frize, J.; Shoham, J.; Kiess, L. Prevention of acute malnutrition: Distribution of special nutritious foods and cash, and addressing underlying causes-What to recommend when, where, for whom, and how. Food Nutr. Bull. 2015, 36 (Suppl. S1), S24-S29. [CrossRef] [PubMed]

50. Semba, R.D.; Trehan, I.; Li, X.; Moaddel, R.; Ordiz, M.I.; Maleta, K.M.; Kraemer, K.; Shardell, M.; Ferrucci, L.; Manary, M. Environmental Enteric Dysfunction is Associated with Carnitine Deficiency and Altered Fatty Acid Oxidation. EBioMedicine 2017, 17, 57-66. [CrossRef] [PubMed]

51. Ordiz, M.I.; Stephenson, K.; Agapova, S.; Wylie, K.M.; Maleta, K.; Martin, J.; Trehan, I.; Tarr, P.I.; Manary, M.J. Environmental Enteric Dysfunction and the Fecal Microbiota in Malawian Children. Am. J. Trop. Med. Hyg. 2017, 96, 473-476. [CrossRef] [PubMed]

52. Watanabe, K.; Petri, W.A., Jr. Environmental Enteropathy: Elusive but Significant Subclinical Abnormalities in Developing Countries. EBioMedicine 2016, 10, 25-32. [CrossRef]

53. Humphrey, J.H. Child undernutrition, tropical enteropathy, toilets, and handwashing. Lancet 2009, 374, 1032-1035. [CrossRef]

54. Null, C.; Stewart, C.P.; Pickering, A.J.; Dentz, H.N.; Arnold, B.F.; Arnold, C.D.; Benjamin-Chung, J.; Clasen, T.; Dewey, K.G.; Fernald, L.C.H.; et al. Effects of water quality, sanitation, handwashing, and nutritional interventions on diarrhoea and child growth in rural Kenya: A cluster-randomised controlled trial. Lancet Glob. Health 2018, 6, e316-e329. [CrossRef]

55. Luby, S.P.; Rahman, M.; Arnold, B.F.; Unicomb, L.; Ashraf, S.; Winch, P.J.; Stewart, C.P.; Begum, F.; Hussain, F.; Benjamin-Chung, J.; et al. Effects of water quality, sanitation, handwashing, and nutritional interventions on diarrhoea and child growth in rural Bangladesh: A cluster randomised controlled trial. Lancet Glob. Health 2018, 6, e302-e315. [CrossRef]

56. Ercumen, A.; Benjamin-Chung, J.; Arnold, B.F.; Lin, A.; Hubbard, A.E.; Stewart, C.; Rahman, Z.; Parvez, S.M.; Unicomb, L.; Rahman, M.; et al. Effects of water, sanitation, handwashing and nutritional interventions on soil-transmitted helminth infections in young children: A cluster-randomized controlled trial in rural Bangladesh. PLoS Negl. Trop. Dis. 2019, 13, e0007323. [CrossRef]

57. Subramanian, S.V.; Ackerson, L.K.; Davey Smith, G.; John, N.A. Association of maternal height with child mortality, anthropometric failure, and anemia in India. JAMA 2009, 301, 1691-1701. [CrossRef]

58. Khatun, W.; Rasheed, S.; Alam, A.; Huda, T.M.; Dibley, M.J. Assessing the Intergenerational Linkage between Short Maternal Stature and Under-Five Stunting and Wasting in Bangladesh. Nutrients 2019, 11, 1818. [CrossRef]

59. Kang, Y.; Kim, J. Risk factors for undernutrition among children 0-59 months of age in Myanmar. Matern. Child Nutr. 2019, 15, e12821. [CrossRef] [PubMed]

60. Kang, Y.; Aguayo, V.M.; Campbell, R.K.; Dzed, L.; Joshi, V.; Waid, J.L.; Gupta, S.D.; Haselow, N.J.; West, K.P., Jr. Nutritional status and risk factors for stunting in preschool children in Bhutan. Matern. Child Nutr. 2018, 14, e12653. [CrossRef] [PubMed]

61. Goudet, S.; Griffths, P.; Bogin, B.A. Mother's body mass index as a predictor of infant's nutritional status in the post-emergency phase of a flood. Disasters 2011, 35, 701-719. [CrossRef] [PubMed]

62. Tigga, P.L.; Sen, J.; Mondal, N. Association of some socio-economic and socio-demographic variables with wasting among pre-school children of North Bengal, India. Ethiop. J. Health Sci. 2015, 25, 63-72. [CrossRef]

63. Ngare, D.K.; Neumann, C. Predictors of low birthweight at the community level. East Afr. Med. J. 1998, 75, 296-299.

64. Ramakrishnan, U. Nutrition and low birth weight: From research to practice 29. Am. J. Clin. Nutr. 2004, 79, 17-21. [CrossRef]

65. Papathakis, P.C.; Singh, L.N.; Manary, M.J. How maternal malnutrition affects linear growth and development in the offspring. Mol. Cell. Endocrinol. 2016, 435, 40-47. [CrossRef]

66. Borja, J.B. The impact of early nutrition on health: Key findings from the Cebu Longitudinal Health and Nutrition Survey (CLHNS). Malays. J. Nutr. 2013, 19, 1-8. 
67. Huybregts, L.; Roberfroid, D.; Lanou, H.; Menten, J.; Meda, N.; Van, C.J.; Kolsteren, P. Prenatal food supplementation fortified with multiple micronutrients increases birth length: A randomized controlled trial in rural Burkina Faso. Am. J. Clin. Nutr. 2009, 90, 1593-1600.

68. Wells, J.C. Adaptive variability in the duration of critical windows of plasticity: Implications for the programming of obesity. Evol. Med. Public Health 2014, 2014, 109-121. [CrossRef]

69. Khan, A.I.; Kabir, I.; Ekstrom, E.C.; Asling-Monemi, K.; Alam, D.S.; Frongillo, E.A.; Yunus, M.; Arifeen, S.; Persson, L.A. Effects of prenatal food and micronutrient supplementation on child growth from birth to 54 months of age: A randomized trial in Bangladesh. Nutr. J. 2011, 10, 134. [CrossRef] [PubMed]

70. Singhal, A.; Wells, J.; Cole, T.J.; Fewtrell, M.; Lucas, A. Programming of lean body mass: A link between birth weight, obesity, and cardiovascular disease? Am. J. Clin. Nutr. 2003, 77, 726-730. [CrossRef] [PubMed]

71. Christian, P.; Lee, S.E.; Donahue, A.M.; Adair, L.S.; Arifeen, S.E.; Ashorn, P.; Barros, F.C.; Fall, C.H.; Fawzi, W.W.; Hao, W.; et al. Risk of childhood undernutrition related to small-for-gestational age and preterm birth in low- and middle-income countries. Int. J. Epidemiol. 2013, 42, 1340-1355. [CrossRef] [PubMed]

72. Kerac, M.; Frison, S.; Connell, N.; Page, B.; McGrath, M. Informing the management of acute malnutrition in infants aged under 6 months (MAMI): Risk factor analysis using nationally-representative demographic \& health survey secondary data. PeerJ 2019, 6, e5848.

73. Adair, L.S.; Martorell, R.; Stein, A.D.; Hallal, P.C.; Sachdev, H.S.; Prabhakaran, D.; Wills, A.K.; Norris, S.A.; Dahly, D.L.; Lee, N.R.; et al. Size at birth, weight gain in infancy and childhood, and adult blood pressure in 5 low- and middle-income-country cohorts: When does weight gain matter? Am. J. Clin. Nutr. 2009, 89, 1383-1392. [CrossRef]

74. Kabore, P.; Potvliege, C.; Sanou, H.; Bawhere, P.; Dramaix, M. Growth velocity and survival of full-term low birth weight infants in an African rural area (Burkina Faso). Arch. Pediatr. 2004, 11, 807-814. [CrossRef]

75. Bhandari, N.; Kabir, A.K.; Salam, M.A. Mainstreaming nutrition into maternal and child health programmes: Scaling up of exclusive breastfeeding. Matern. Child Nutr. 2008, 4 (Suppl. S1), 5-23. [CrossRef]

76. Kerac, M.; Mwangome, M.; McGrath, M.; Haider, R.; Berkley, J.A. Management of acute malnutrition in infants aged under 6 months (MAMI): Current issues and future directions in policy and research. Food Nutr. Bull. 2015, 36 (Suppl. S1), S30-S34. [CrossRef]

77. Munirul Islam, M.; Arafat, Y.; Connell, N.; Mothabbir, G.; McGrath, M.; Berkley, J.A.; Ahmed, T.; Kerac, M. Severe malnutrition in infants aged $<6$ months-Outcomes and risk factors in Bangladesh: A prospective cohort study. Matern. Child Nutr. 2019, 15, e12642.

78. Centre UI. Poverty abd Exclusion among Urban Children; UNICEF, Ed.; Innocenti Research Centre: Florence, Italy, 2002.

79. Tada, Y.; Keiwkarnka, B.; Pancharuniti, N.; Chamroonsawasdi, K. Nutritional status of the preschool children of the Klong Toey slum, Bangkok. Southeast Asian J. Trop. Med. Public Health 2002, 33, 628-637.

80. Rahman, M.S.; Rahman, M.A.; Maniruzzaman, M.; Howlader, M.H. Prevalence of undernutrition in Bangladeshi children. J. Biosoc. Sci. 2019, 1-14. [CrossRef] [PubMed]

81. Lu, Y.; Nakicenovic, N.; Visbeck, M.; Stevance, A.S. Five priorities for the UN sustainable development goals. Nature 2015, 520, 432-433. [CrossRef] [PubMed]

82. Gillespie, S.; Haddad, L.; Mannar, V.; Menon, P.; Nisbett, N.; Maternal and Child Nutrition Study Group. The politics of reducing malnutrition: Building commitment and accelerating progress. Lancet 2013, 382, 552-569. [CrossRef]

83. Menon, P. Childhood undernutrition in south Asia: Perspectives from the field of nutrition. CESifo Econ. Stud. 2012, 58, 274-295. [CrossRef]

84. Hokken-Koelega, A.C.; De Ridder, M.A.; Lemmen, R.J.; Den Hartog, H.; De Muinck Keizer-Schrama, S.M.; Drop, S.L. Children born small for gestational age: Do they catch up? Pediatr. Res. 1995, 38, $267-271$. [CrossRef] [PubMed]

(C) 2020 by the authors. Licensee MDPI, Basel, Switzerland. This article is an open access article distributed under the terms and conditions of the Creative Commons Attribution (CC BY) license (http://creativecommons.org/licenses/by/4.0/). 